\title{
Children with Dry Skin and Atopic Predisposition: Outcome Measurement with Validated Scores for Atopic Dermatitis
}

\author{
Sabine Sawatzky ${ }^{a} \quad$ Marianne Schario $^{a} \quad$ Andrea Stroux $^{a, b}$ Lena Lünnemann ${ }^{a}$ \\ Torsten Zuberbier ${ }^{c} \quad$ Ulrike Blume-Peytavi ${ }^{\mathrm{a}} \quad$ Natalie Garcia Bartels ${ }^{\mathrm{a}}$ \\ a Department of Dermatology and Allergy, Clinical Research Center for Hair and Skin Science, \\ ${ }^{b}$ Department of Biometry and Clinical Epidemiology, and ${ }^{C} E C A R F$ Institute GmbH, Allergie-Centrum-Charité, \\ Charité - Universitätsmedizin Berlin, Berlin, Germany
}

\section{Key Words}

Atopic dermatitis · Dry skin - Microtopography .

Patient-Oriented SCORing Atopic Dermatitis · Pediatric atopy · Severity Scoring of Atopic Dermatitis · Skin barrier function

\section{Abstract \\ Background: Dry skin is a common skin condition in child- hood. Few studies exist investigating the influence of daily skin care on dry skin in infants at risk of developing atopic dermatitis (AD). We aimed to assess the effect of skin care on dry skin in this special cohort using validated scores for $A D$ and analysis of skin microtopography. Methods: 43 children were randomized to group 1 (G1) and group 2 (G2) and 22 infants to group 3 (G3). During 16 weeks, G1 and G3 applied daily a plant-based emollient and G2 a petrolatum-based emollient. The core outcome was assessed by Severity Scor- ing of Atopic Dermatitis (SCORAD) and Patient-Oriented SCORing Atopic Dermatitis (PO-SCORAD). The influence on the parents' life was evaluated by a questionnaire and micro- topography by Visioscan ${ }^{\circledR}$ VC 98. Results: The SCORAD in- dex declined significantly until week (W) 16 in all groups ( $p$ $\leq 0.041$ ). The sleeplessness score analyzed by PO-SCORAD was highly reduced after $\mathrm{W} 12$ in $\mathrm{G} 1$ and after $\mathrm{W} 16$ in $\mathrm{G} 2$ ( $\mathrm{p} \leq$}

0.030). The influence on the parents' anxiety was reduced in G3 at W12 and W16 $(p=0.016)$. The Visioscan parameter scaliness strongly diminished at W4 ( $p \leq 0.049)$ and W16 ( $\leq$ 0.013 ) in all groups. Conclusions: This trial demonstrates improved skin conditions and sleep following daily emollient application in infants and children having dry skin and being at risk of AD. Especially parents of infants showed a reduced fear that their children might develop AD. Further studies are required to investigate the preventive effect of daily emollient therapy in this special cohort evaluating the outcome measures used in this trial.

(c) 2016 S. Karger AG, Basel

\section{Introduction}

Dry skin is a common skin condition in infants and children who may develop or already have atopic dermatitis (AD) [1-4]. Especially infants with at least one parent or sibling meeting the criteria of $\mathrm{AD}$ in the past or present have been previously defined as being at high risk to develop atopic disease in childhood [1,5]. Daily emollient use from birth on may represent a feasible approach for

S.S. and M.S. contributed equally to this paper.

Priv.-Doz. Dr. med. Natalie Garcia Bartel

Department of Dermatology and Allergy, Clinical Research Center for Hair and Skin Science Charité - Universitätsmedizin Berlin, Charitéplatz 1 DE-10117 Berlin (Germany)

E-Mail natalie.garcia-bartels@ charite.de 
the primary prevention of $\mathrm{AD}$ especially in these highrisk infants $[1,6]$. However, evidence-based recommendations for the management of this target group are still missing. Therefore, a scientific approach to objectively quantify the effects of daily skin care is mandatory. Although many data exist on infants affected by AD, only few clinical studies have quantified or qualified the effect of daily emollient use especially in infants having dry skin and being at risk to develop AD. Recently, a comparison of two different emollients revealed significant effects on skin barrier function [7]. Furthermore, clinical trials especially focusing on children already affected by AD recommend the evaluation of atopic signs and quality of life [8]. However, specific assessment scores of these domains are not available for this special cohort of infants who are predisposed to $\mathrm{AD}$ development but not yet affected. So far, the best validated instruments to measure and monitor activity of AD in clinical trials are the Eczema Area Severity Index and the Severity Scoring of Atopic Dermatitis (SCORAD) [9]. Especially for infants, the SCORAD seems to be appropriate, as it is the most widely used disease severity scale for all age groups, starting from birth [10-14]. This score combines an assessment of disease extent and intensity, including dryness of unharmed skin, and is called objective SCORAD. In addition, a visual analogue score for pruritus and sleeplessness can be performed to evaluate AD symptoms. The index which considers both is the subjective SCORAD $[9,15,16]$. As the SCORAD comprises the recommended core outcome measure and the intensity of dry skin, it may be a useful method to evaluate the outcome of interventions in infants and children with dry skin and atopic predisposition as well [8].

Moreover, the infant's signs, symptoms, and quality of life are also transmitted by the parents to the investigator. The affection of their children often has a direct impact on their own quality of life [17]. The Patient-Oriented SCORing Atopic Dermatitis (PO-SCORAD) represents a self-assessment score to involve parents in effective skin monitoring $[13,18]$. Sharing a comparable analytic factor as the SCORAD, the PO-SCORAD facilitates the communication between parents and physicians [19-22].

So far, a specific questionnaire evaluating symptoms like emotional distress, sleeplessness, and increased concerns of parents who have children predisposed to $\mathrm{AD}$ development is not available to our knowledge.

Therefore, we aimed to objectively evaluate the core outcomes in this defined population using validated scores for measuring the effect of daily emollient application on the development of AD. An accompanying mea- surement of surface evaluation of living skin (SELS) was performed to correlate the clinical scores to biophysical data quantifying properties like scaliness $[23,24]$.

\section{Methods}

Study Design

A subcohort of 43 children (aged 2-6 years \pm 4 weeks) and 22 infants (aged 3-12 months \pm 4 weeks) with dry skin and atopic predisposition involved in a clinical study conducted at our study center between 2011 and 2012 was analyzed [7] for the following parameters: SCORAD; PO-SCORAD; influence on the parents' quality of life, and skin microtopography.

The design of the study [7] consisted of an active application phase lasting 16 weeks. Participants were examined at study entry (baseline) and at week $4 \pm 4$ days (W4), week $12 \pm 4$ days (W12) and week $16 \pm 7$ days (W16). At each visit, the SCORAD was assessed; parents were asked to complete the PO-SCORAD and a questionnaire on the effect on the parents' quality of life. The selfassessment questionnaires were completed prior to the physical examination and before imaging of skin microtopography [7]. The trial was approved by the local ethics committee.

\section{Population}

Participants with dry skin and atopic predisposition (modified Erlanger Atopy Score $\geq 4)[25,26]$ were included. In addition, one or both parents of the participants had a current or previous history of AD, allergic rhinitis, conjunctivitis, or asthma [7]. Exclusion criteria for the present analysis were a current or previous $\mathrm{AD}$, immunocompromised disease or severe illness, increased or decreased body temperature $\left(\leq 35\right.$ or $\left.\geq 38.5^{\circ} \mathrm{C}\right)$, congenital and/or contagious skin disorders, skin irritation affecting measurements, current treatment with topical or systemic corticosteroids or macrolides, any topical or systemic therapy within 4 months prior to study entry for more than 3 days with corticosteroids, pimecrolimus, antihistamine, and/or further phototherapy, and participation in another study. After obtaining written informed consent from both legal guardians, eligible children were randomly assigned to one of two different intervention groups [children group 1 (G1) and children group 2 (G2)] using concealed random allocation by a person not being involved in the study. Eligible infants were assigned to infant group 3 (G3). Randomization was performed by using block randomization with a block length of four [7].

\section{Intervention}

The three intervention groups consisted of two groups of children (G1 and G2) and one group of infants (G3) [7]. G1 and G3 received plant-based skin care with two different formulated emollients; the cream had a higher content of natural lipids and plant extract compared to the lotion. Both skin care formulations are available in pharmacies and health stores. The control group (G2) received basic skin care treatment with a petrolatum-based lotion and cream (German Drug Codex, DAC basic cream). Both are adjusted in their lipid and ethanol concentration to the lotion or cream base used in G1 and G3.

The lotion was applied to the entire body surface excluding the face. The face only received cream. The forearm received cream as well as lotion. 
Table 1. Influence on the quality of life of parents with children having dry skin and atopic predisposition

\begin{tabular}{|c|c|c|}
\hline \multicolumn{2}{|r|}{ Influence on parents' quality of life } & \multirow{2}{*}{$\begin{array}{l}\text { Intensity } \\
\text { Not at all } \\
\text { A little } \\
\text { A lot } \\
\text { Very much }\end{array}$} \\
\hline 1 & $\begin{array}{l}\text { Over the last week, approximately how } \\
\text { much was your sleep on average disturbed } \\
\text { each night because of your child? }\end{array}$ & \\
\hline 2 & $\begin{array}{l}\text { Over the last week, has your child's } \\
\text { eczema interfered in taking part or } \\
\text { enjoying family activities? }\end{array}$ & $\begin{array}{l}\text { Yes } \\
\text { No } \\
\text { n.a. }\end{array}$ \\
\hline 3 & $\begin{array}{l}\text { Over the last week, how many consultations } \\
\text { were needed because of your child's skin } \\
\text { disease? }\end{array}$ & $\begin{array}{l}\text { None } \\
1 / \text { year } \\
5 / \text { year } \\
>5 / \text { year }\end{array}$ \\
\hline 4 & $\begin{array}{l}\text { Over the last week, were you very anxious } \\
\text { that your child may develop AD? }\end{array}$ & $\begin{array}{l}\text { Yes } \\
\text { No } \\
\text { n.a. }\end{array}$ \\
\hline 5 & $\begin{array}{l}\text { Over the last week, how much has the skin } \\
\text { of your child influenced your everyday life? }\end{array}$ & $\begin{array}{l}\text { Not at all } \\
\text { A little } \\
\text { A lot } \\
\text { Very much }\end{array}$ \\
\hline 6 & $\begin{array}{l}\text { Have there been problems with your child } \\
\text { due to treatment over the last week? }\end{array}$ & $\begin{array}{l}\text { Yes } \\
\text { No } \\
\text { n.a. }\end{array}$ \\
\hline
\end{tabular}

n.a. $=$ Not applicable.

Study products (Ice Plant Body Care Lotion, Intensive Ice Plant cream, Dr. Hauschka Med, and DAC cream and lotion) were manufactured and labelled by WALA Heilmittel GmbH (Bad Boll, Germany). No other emollients were allowed except sun cream. However, parents were instructed to use physical sun protection. They were advised to retain their routine bathing procedures with the usual cleaning products. The last application of emollients was more than $12 \mathrm{~h}$ before assessments [7].

\section{Outcome Variables and Clinical Evaluations}

All measurements were performed under controlled conditions (room temperature between 22 and $26^{\circ} \mathrm{C}$, and relative humidity of 40-60\%) after an acclimatization period of at least $10 \mathrm{~min}$.

\section{SCORAD}

In the subcohort, the SCORAD index was assessed to quantify the clinical severity of skin conditions including dryness and using this established score for $\mathrm{AD}$ to measure the recommended core outcomes $[9,11-13]$. The same investigator assessed and analyzed subjective and objective items separately. The percentage of body surface involved was recorded by the 6 intensity items dryness on unharmed skin, erythema, edema/papule, oozing/crust, excoriation, and lichenification for computation of the objective SCORAD value. The severity score ranges from 0 to $3(0=$ absent, $1=$ mild, $2=$ moderate, and $3=$ severe) for these items. Special require- ments for calculating SCORAD were considered for children younger than 2 years.

The subjective parameters pruritus and sleeplessness were assessed by using a visual scale ranging from 0 to 10 [11]. The objective SCORAD was calculated without these two subjective items. Although the SCORAD does not evaluate an extent of less than 3\% of skin involved, the special cohort was analyzed irrespective of the $3 \%$ condition [27].

\section{PO-SCORAD}

The PO-SCORAD is a self-assessment score with effective skin condition monitoring for patients or their parents $[13,18]$. Content and measurement properties of the PO-SCORAD are based on the SCORAD and can be separated into 3 parts - assessment of disease extent, severity, and evaluation of subjective symptoms. At each visit, the parents filled in the PO-SCORAD form using an illustrated guidance booklet.

\section{Influence on the Parents' Quality of Life}

The Dermatitis Family Impact Questionnaire (DFI), the Dermatology Quality of Life Index and the Infants' Dermatology Quality of Life Index are questionnaires to assess the quality of life of patients with $\mathrm{AD}$ and their family $[14,28]$. Our questionnaire was derived from the validated DFI [28] and adapted to the study purposes using comparable categories as in the DFI. The questions are represented in table 1 .

\section{Skin Microtopography}

Skin surface analysis by Visioscan ${ }^{\circledR}$ VC 98 (Courage + Khazaka electronic GmbH, Köln, Germany) according to the SELS method is based on the evaluation of an image of living skin taken under certain illumination. The image of the skin is taken by a built-in charge-coupled device camera. The pictures are electronically processed for quantitative analyses. The Visioscan ${ }^{\circledR}$ has two halogenide lights arranged on opposite sides to illuminate the skin uniformly. The spectrum of the lamps and their intensity as well as their location enables the analysis of the skin surface without interfering of reflections from deeper layers. By means of the additional software (SELS), different parameters can be calculated. In our subcohort, the parameters scaliness contributing to skin dryness, roughness, smoothness, and wrinkles were assessed on the right leg at each visit by Visioscan ${ }^{\circledR}$. If the right leg could not be assessed at study entry, the left side of the body was chosen for the measurements [23].

\section{Study Protocol}

The full trial protocol can be obtained from the Department for Dermatology and Allergy, Clinical Research Center for Hair and Skin Science, Charité - Universitätsmedizin Berlin.

\section{Statistical Analysis}

Data are described as absolute and relative frequencies for categorical variables, and as means \pm SD for quantitative measurements. Between-group comparisons were performed using the $\chi^{2}$ test for categorical and the Mann-Whitney U test for quantitative variables. Accordingly, McNemar and the Wilcoxon signed rank test were used to test for differences between variable time points concerning the investigated scores. Values of $\mathrm{p} \leq 0.05$ are considered significant; Bonferroni correction has not been performed. All statistical analyses were done with the commercially available software SPSS 21. 
Table 2. Baseline characteristics of the study participants according to the study group

\begin{tabular}{lcrc}
\hline Characteristics & $\begin{array}{l}\mathrm{G} 1 \\
(\mathrm{n}=22)\end{array}$ & $\begin{array}{l}\mathrm{G} 2 \\
(\mathrm{n}=21)\end{array}$ & $\begin{array}{l}\mathrm{G} 3 \\
(\mathrm{n}=22)\end{array}$ \\
\hline Erlanger Atopy Score (mean $\pm \mathrm{SD})$ & $8.68 \pm 2.44$ & $8.48 \pm 2.73$ & $7.82 \pm 2.26$ \\
Females, $\mathrm{n}(\%)$ & $14(63.6)$ & $9(42.9)$ & $11(50.0)$ \\
Males, $\mathrm{n}(\%)$ & $8(36.4)$ & $12(57.1)$ & $11(50.0)$ \\
Mature birth, $\mathrm{n}(\%)$ & $20(90.9)$ & $21(100.0)$ & $15(68.2)$ \\
Premature birth, $\mathrm{n}(\%)$ & $2(9.1)$ & $0(0)$ & $7(31.8)$ \\
Age (mean \pm SD), months & $47.86 \pm 12.15$ & $38.62 \pm 15.12$ & $7.64 \pm 2.68$ \\
Allergy type I + IV infant, $\mathrm{n}$ & $2(9.1)$ & $4(19.0)$ & $0(0)$ \\
\hline AD: mother (childhood), $\mathrm{n}(\%)$ & $7(31.8)$ & $5(23.8)$ & $7(31.8)$ \\
AD: father (childhood), $\mathrm{n}(\%)$ & $2(9.1)$ & $4(19.0)$ & $3(13.6)$ \\
AD: mother, $\mathrm{n}(\%)$ & $5(22.7)$ & $3(14.3)$ & $5(22.7)$ \\
AD: father, $\mathrm{n}(\%)$ & $3(13.6)$ & $3(14.3)$ & $4(18.2)$ \\
\hline Other eczema: mother, $\mathrm{n}(\%)$ & $6(27.3)$ & $6(28.6)$ & $2(9.1)$ \\
Other eczema: father, $\mathrm{n}(\%)$ & $6(27.3)$ & $5(23.8)$ & $1(4.5)$ \\
\hline Allergic rhinitis: mother, $\mathrm{n}(\%)$ & $13(59.1)$ & $12(57.1)$ & $10(45.5)$ \\
Allergic rhinitis: father, $\mathrm{n}(\%)$ & $9(40.9)$ & $10(47.6)$ & $13(59.1)$ \\
Allergic conjunctivitis: mother, $\mathrm{n}(\%)$ & $11(50.0)$ & $9(42.9)$ & $7(31.8)$ \\
Allergic conjunctivitis: father, $\mathrm{n}(\%)$ & $8(36.4)$ & $8(38.1)$ & $10(45.5)$ \\
\hline Asthma: mother, $\mathrm{n}(\%)$ & $4(18.2)$ & $4(19.0)$ & $4(18.2)$ \\
Asthma: father, $\mathrm{n}(\%)$ & $2(9.1)$ & $5(23.8)$ & $5(22.7)$ \\
\hline Allergy type I + IV: mother, $\mathrm{n}(\%)$ & $10(45.5)$ & $11(52.4)$ & $7(31.8)$ \\
Allergy type I + IV: father, $\mathrm{n}(\%)$ & $3(13.6)$ & $9(42.9)$ & $5(22.7)$ \\
\hline
\end{tabular}

\section{Results}

Baseline characteristics of the 43 children (G1, $n=22$ and $\mathrm{G} 2, \mathrm{n}=21$ ) and 22 infants (G3) are presented in table 2 .

During the study period, 1 child dropped out at each visit $(\mathrm{V})$ in $\mathrm{G} 1$. The reasons were the use of topical corticosteroids longer than 3 days (V1 and V3) and the request of the participant (V2). In G2, 4 children dropped out due to loss of contact (V1), time difficulties (V2), consent withdrawal (V2), and the use of topical corticosteroids longer than 3 days (V3). In G3, 1 infant dropped out at V2 because parents wished to discontinue the study due to the development of a skin rash [7].

\section{SCORAD}

The SCORAD index (subjective SCORAD) and the objective SCORAD declined significantly until W16 in all groups ( $\mathrm{p} \leq 0.041)$ except for the SCORAD index in G3 at W12 ( $\mathrm{p}=0.056$; fig. 1$)$. No group-specific differences were observed.
At study entry, $75.8 \%$ of the entire sample had an extent of dry skin $<3 \%$. At the end of the study, $93 \%$ had an extent of involved skin $<3 \%$; the percentage of participants with an extent of dry skin $\geq 3 \%$ declined from 24.2 to $7 \%$ at the end of the study (fig. $2 a$ ).

Significant reductions in subjective and objective parameters were found when analyzing the different items of the SCORAD index. The extent of involved skin was decreased in all participants irrespective of the $3 \%$ at W 12 in $\mathrm{G} 2(\mathrm{p}=0.027)$ and W16 in $\mathrm{G} 3(\mathrm{p}=0.020)$ with a significant difference between $\mathrm{G} 1$ and $\mathrm{G} 3$ at V1 and G2 and G3 at V2 (p $\leq 0.018$; fig. 2a). The extent of involved skin showed a range from 0 to $41.5 \%$ at study entry and from 0 to $16.0 \%$ at the end of the study. The objective intensity parameters showed a significantly reduced erythema score in G3 until W16 (p $\leq 0.045$; fig. 2b) and a significantly declined dryness score in all groups until W16 ( $p \leq 0.035$; fig. 2c). There were no significant differences between the groups. The scores of edema, excoriation, oozing/crust or lichenification showed no significant differences between the groups $(\mathrm{p} \geq 0.107)$ until W16 ( $\mathrm{p} \geq$ $0.063)$. 


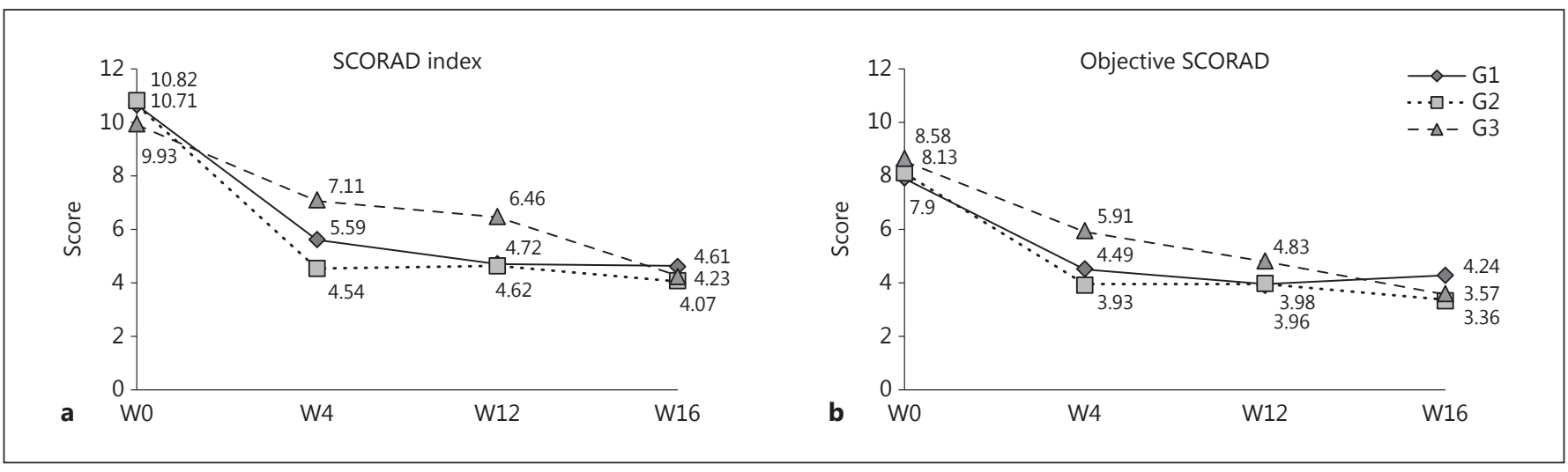

Fig. 1. Reductions in the SCORAD index (including subjective and objective signs and symptoms; a) and objective SCORAD (excluding the subjective symptoms sleepless and pruritus; b).
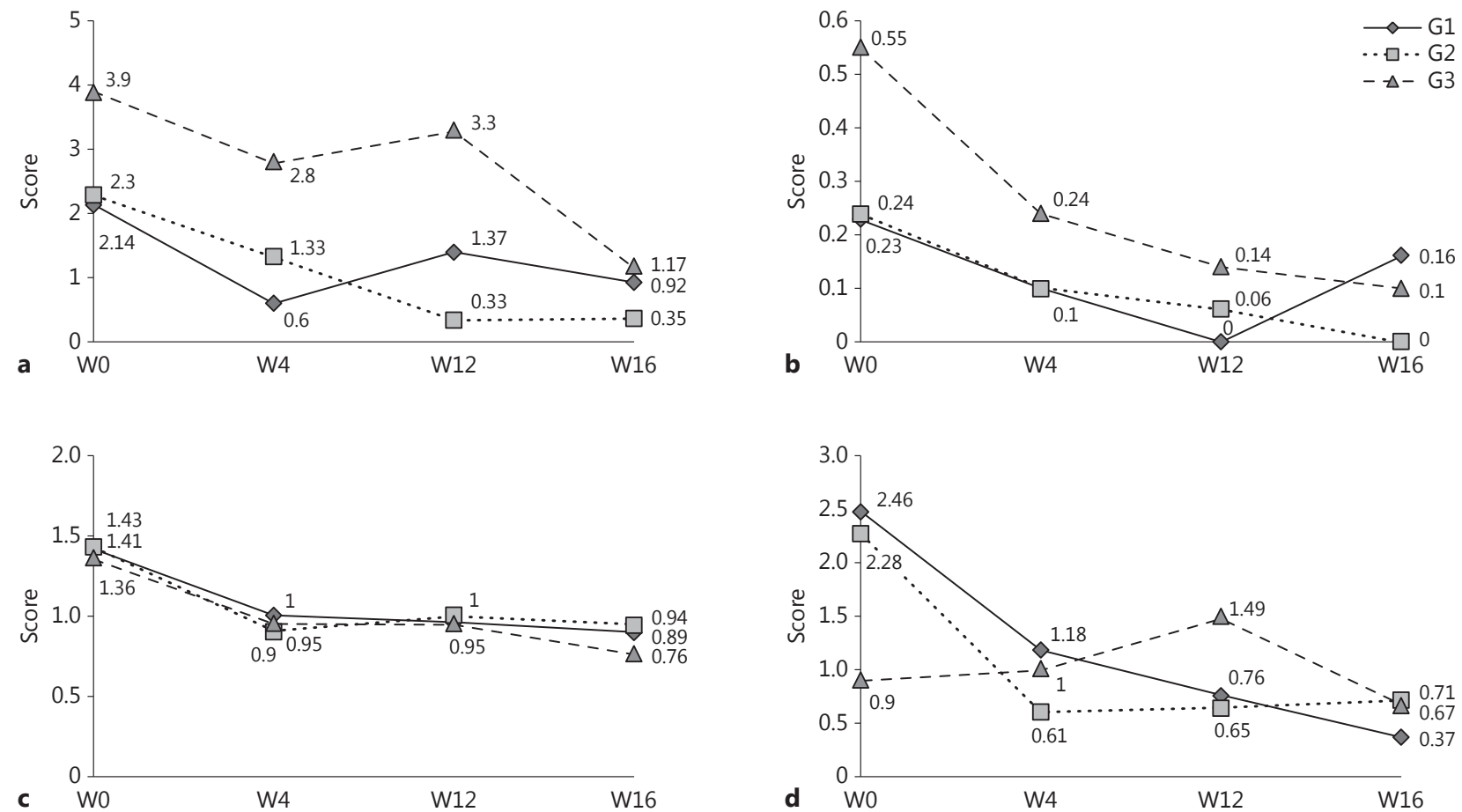

Fig. 2. Significant reductions in subjective and objective items of the SCORAD index. a Involved skin. b Erythema. c Dryness. d Pruritus.

Analyzing the subjective parameters, the pruritus score was significantly decreased at W4, W12, and W16 in G1 and G2 ( $\mathrm{p} \leq 0.030$; fig. $2 \mathrm{~d}$ ). At baseline, the pruritus score was significantly higher in G1 $(2.46 \pm 2.3)$ and G2 (2.28 \pm 2.5$)$ compared to G3 $(0.9 \pm 1.3 ; \mathrm{p} \leq 0.043)$.
There were no significant differences at the end of the study.

The score sleeplessness represented no significant differences in all groups $(p \geq 0.125)$ and between the groups $(\mathrm{p} \geq 0.232)$. 

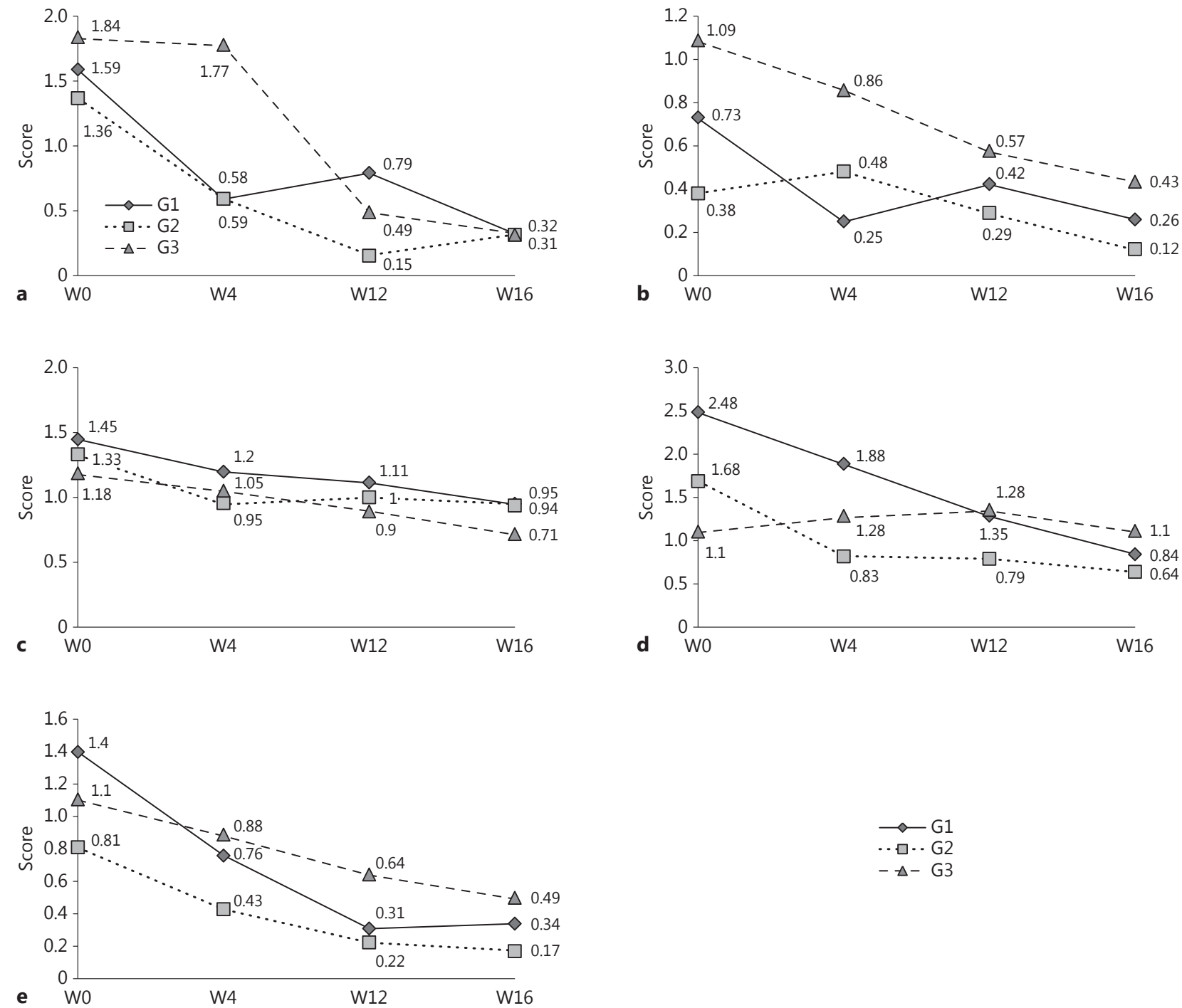

Fig. 3. Significant PO-SCORAD score reductions in involved skin (a), erythema (b), dryness (c), pruritus (d) and sleeplessness (e) of predisposed infants and children having dry skin.

PO-SCORAD

The score of the involved body surface diminished in $\mathrm{G} 3(\mathrm{p}=0.003)$ after $\mathrm{W} 12$ and in G3 as well as G1 after $\mathrm{W} 16$ ( $\mathrm{p} \leq 0.008$; fig. 3a). There were significant differences between $\mathrm{G} 2$ and $\mathrm{G} 3$ at baseline $(\mathrm{p}=0.025)$ and between G1 and G2 compared to G3 at W4 (p $\leq 0.009$ ). In G1 and G3, the erythema score was reduced at W16 (p s 0.047 ) with significant differences between $\mathrm{G} 1$ and $\mathrm{G} 3$ at $\mathrm{W} 12(\mathrm{p}=0.008)$ and between $\mathrm{G} 2$ and G3 at W4 $(\mathrm{p}=0.009$; fig. 3b). The dryness score decreased in G1 at W16 (p =
0.012 ) and in $\mathrm{G} 2$ at $\mathrm{W} 4$ ( $\mathrm{p}=0.035$; fig. $3 \mathrm{c})$. In $\mathrm{G} 1$, the pruritus score dropped at W12 and W16 (p $\leq 0.049)$ and in G2 at W4 and W16 ( $1 \leq 0.030)$ with significant differences between $\mathrm{G} 1$ and $\mathrm{G} 3$ at baseline ( $\mathrm{p}=0.015$; fig. $3 \mathrm{~d}$ ). The score of sleeplessness was significantly reduced in G1 after W12 $(\mathrm{p}=0.030)$ and in G2 after W16 $(\mathrm{p}=0.016$; fig. 3e). There were significant differences between G2 and G3 at W4 $(\mathrm{p}=0.034)$ and W16 $(\mathrm{p}=0.027)$. The parameter scratching dropped significantly $(\mathrm{p}=0.047)$ after $\mathrm{W} 4(\mathrm{~V} 1=0.05 \pm 0.224)$ and $\mathrm{W} 16(\mathrm{p}=0.031, \mathrm{~V} 3=0.16 \pm$ 


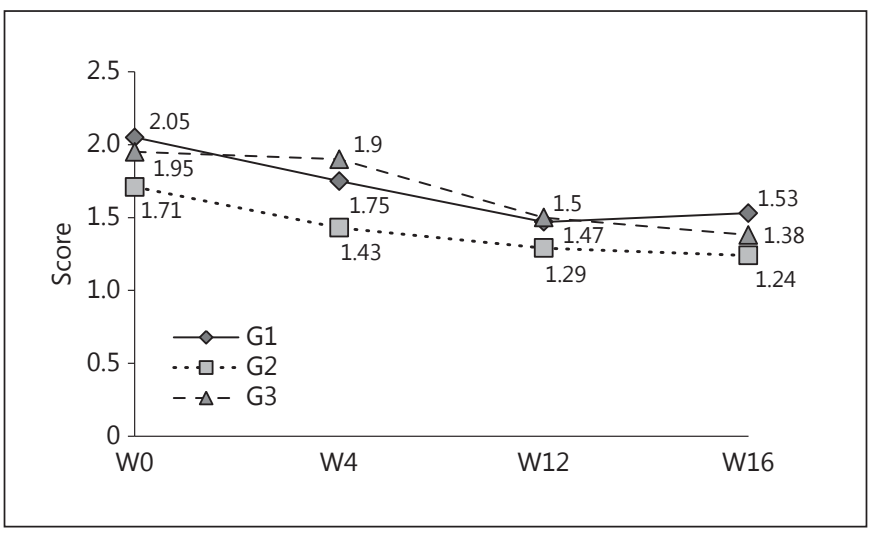

Fig. 4. Significant improvement in parents' sleep.

$0.501)$ in $\mathrm{G} 1$ compared to baseline $(\mathrm{V} 0=0.50 \pm 0.74)$. The parameters of edema, oozing, crust, hyperplasia, hemorrhage, fissure, and scaling showed no significant results in the group comparison ( $\mathrm{p} \geq 0.233$ ) until W16 ( $\mathrm{p} \geq$ $0.125)$.

\section{Influence on the Parents' Life}

The impact on the parents' sleep was significantly reduced after W12 in G1 ( $\mathrm{p}=0.008)$ and $\mathrm{W} 16$ in all groups ( $\mathrm{p} \leq 0.016$; fig. 4). In G3, the anxiety of the parents that infants may develop atopic disease decreased significantly from $73.7 \%$ (14 of 22 parents) at study entry to $33.3 \%$ (6 of 21 parents) at W12 and W16 ( $\mathrm{p}=0.016)$. The other questions indicated no significant differences during the 16-week intervention ( $\mathrm{p} \geq 0.125)$.

\section{Skin Microtopography}

The parameter scaliness measured at the right midlateral thigh was significantly diminished in all groups at $\mathrm{W} 4$ ( $\mathrm{p} \leq 0.049)$ and W16 (p $\leq 0.013)$, and additionally in $\mathrm{G} 2$ at $\mathrm{W} 12$ ( $\mathrm{p}=0.005$; fig. 5$)$. There were significant differences between $G 1$ and $G 2$ at baseline $(p=0.026)$ and between G2 and G3 at baseline $(\mathrm{p}=0.011)$ and W16 $(\mathrm{p}=$ $0.007)$. The parameter smoothness was significantly reduced in G3 at W12 (V2 = 28.59 $\pm 6.33, \mathrm{p}=0.003)$ compared to V0 (36.48 \pm 14.65$)$. The wrinkles increased significantly $(\mathrm{p} \leq 0.003)$ in $\mathrm{G} 3$ at W4 $(\mathrm{V} 1=47.77 \pm 9.17)$ and $\mathrm{W} 16(\mathrm{~V} 3=47.56 \pm 6.16)$ compared to baseline (V0 = $41.42 \pm 5.52)$ and decreased in $\mathrm{G} 1$ at $\mathrm{W} 16(\mathrm{~V} 3=36.41 \pm$ $3.91, \mathrm{p}=0.026)$ compared to V0 $(39.31 \pm 4.52)$. Significant differences $(\mathrm{p} \leq 0.007)$ between G1 (38.97 \pm 5.33$)$ and G2 (40.74 \pm 4.10$)$ compared to G3 (47.77 \pm 9.17$)$ were observed at W4, W12 $(\mathrm{G} 1=38.00 \pm 5.21, \mathrm{G} 2=41.45 \pm$

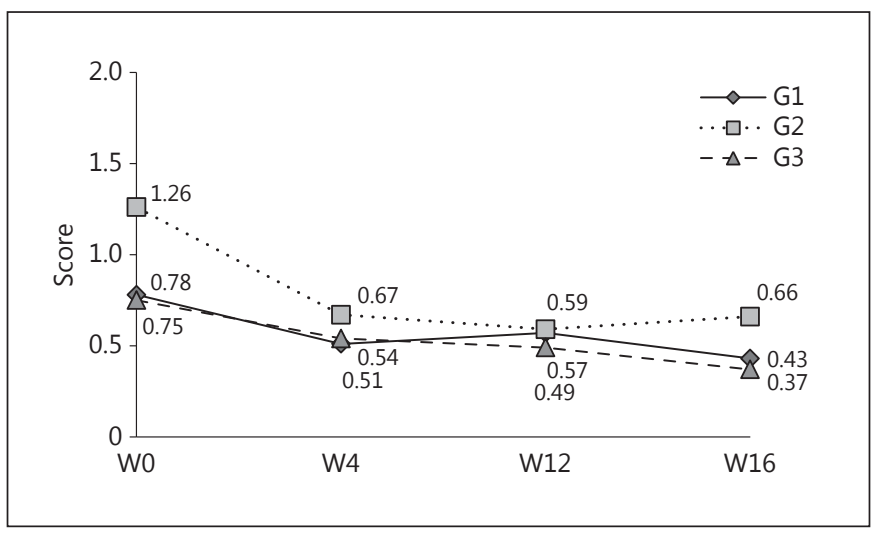

Fig. 5. Significant reductions in the microtopography parameter scaliness in all groups starting at W4 until W16.

$6.36, \mathrm{G} 3=46.31 \pm 6.11), \mathrm{W} 16(\mathrm{G} 1=36.41 \pm 3.91, \mathrm{G} 2=$ $38.54 \pm 3.31, \mathrm{G} 3=47.56 \pm 6.16)$ and between G1 and G2 at $\mathrm{W} 16(\mathrm{p}=0.029)$. The parameter roughness showed no significant differences. However, significant ( $\mathrm{p} \leq 0.046)$ differences exist between G1 (1.03 \pm 0.49$)$ and G2 (1.11 \pm $0.64)$ compared to $\mathrm{G} 3(0.92 \pm 1.18)$ at $\mathrm{W} 12$ and $\mathrm{W} 16$ $(\mathrm{p} \leq 0.028, \mathrm{G} 1=1.09 \pm 0.47, \mathrm{G} 2=1.32 \pm 0.67, \mathrm{G} 3=0.84$ $\pm 0.78)$.

\section{Discussion}

While guidelines for the treatment of children with manifest AD already exist [29, 30], no standardized recommendations for skin care are available for infants and children with atopic predisposition.

Previous data on this target group revealed the development of improved skin barrier function following daily emollient application [7]. In addition, Simpson et al. [1, 6] suggested that a daily application of a moisturizer from birth on may prevent the development of AD. Therefore, emollient therapy for the primary prevention of $\mathrm{AD}$ is now in the focus of research. The challenge in primary prevention is the definition of an incident case of $A D$ and standardized outcome measures in $\mathrm{AD}$ research [31]. The recommended outcome measurements for $\mathrm{AD}$ also showed significant improvement in the condition of dry skin.

The SCORAD index is a valid score to quantify the extent and the intensity of clinical signs of $\mathrm{AD}$, including dryness of unharmed skin and the severity of AD symptoms [9]. In accord with previous studies on the SCORAD index and AD prevalence in children, we also found 
an index in our subcohort categorized as mild at baseline $[32,33]$. Despite this low SCORAD index, children and infants registered a positive and a significant benefit of the skin care regimes in our trial. During the 16-week treatment, the SCORAD index and the objective SCORAD decreased significantly in all groups (fig. 1), with the greatest improvement noticed for skin dryness (fig. 2c) followed by erythema (fig. 2b), and reduction in the extent of involved skin (fig. 2a). Additionally, the amount of participants having an extent of involved skin $\geq 3 \%$ dropped from 24 to $7 \%$ at the end of the study. Xerosis has a high prevalence in childhood and is one of the most important signs in $\mathrm{AD}$ [2]. Both skin care regimes significantly reduced the SCORAD item intensity of skin dryness (fig. 2c) in all groups and of pruritus (fig. 2d) in both groups of children (G1 and G2). It has been shown that in children with manifest AD the improvement in xerosis by an emollient therapy resulted in a decreased objective SCORAD [34] and a subsequent decrease in the risk to develop percutaneous sensitization [35-37].

Furthermore, biophysical parameters represent an important adjunct in the comprehensive evaluation of emollient effects on skin barrier function $[7,38]$. The skin microtopography confirmed the decrease in skin dryness measured by the SCORAD showing a significantly diminished scaling on the leg in all groups (G1-G3; fig. 5). These results indicate an improved skin condition by daily application of emollients.

Correcting subclinical skin barrier dysfunction by improving skin hydration in predisposed infants seems to be an important approach to reduce the risk to develop $\mathrm{AD}$ in childhood $[6,7]$.

In addition to objective parameters of $\mathrm{AD}$ assessed by the investigator, it is of increasing interest to involve patients in the treatment process $[9,19]$. The PO-SCORAD is a validated score to comprehensively assess AD symptoms and severity by patients or parents (on behalf of the children) and seems to correlate with the SCORAD [13, $21]$. The PO-SCORAD showed a trend to decreases in the clinical sign dryness and the symptom pruritus, as seen in the course of the SCORAD. Moreover, during the 16week intervention, the PO-SCORAD significantly decreased for involved skin (fig. 3a) and erythema (fig. 3b). However, the appraisement of the symptom sleeplessness by the parents differs between PO-SCORAD and SCORAD in the present study [22]. The sleeplessness score was significantly reduced (fig. 3e) in G1 at W12 and G2 at $\mathrm{W} 16$ using the PO-SCORAD in contrast to no significant outcome in the SCORAD. In addition to the POSCORAD, we distributed a questionnaire to assess the in- fluence on parent's life. In this study, the daily emollient application showed a positive impact on the parents' sleep with a significant improvement in all groups at each visit (fig. 4). This result is supported by a significant improvement in sleep in the PO-SCORAD. Interestingly, the influence on the parents' anxiety was obviously restricted to infants with a significant decrease at W12 and W16. The treatment of dry skin seems to improve the quality of life in our cohort $[39,40]$. Involving the parents in the observation of the symptoms and severity of dry skin may help parents build confidence and enhance their compliance with regular, possibly preventive skin care.

As shown previously, daily skin care revealed a significant improvement in skin barrier function measured by biophysical techniques in children with dry skin and atopic predisposition [7]. In this study, significant improvements in the symptoms and severity in this specific cohort were determined using outcome measures for $\mathrm{AD}$ trials. Moreover, a significant improvement in the sleep of the children and their parents was observable. The present results may help to develop standardized skin care recommendations for infants predisposed to atopy. Additionally, the results may contribute to the definition of standardized outcome measures for future trials considering infants with atopic predisposition and dry skin, and therefore might close the current gap [8].

Thus, increasing awareness of dry skin in infancy and childhood by pediatricians and parents may help to lower the risk of developing AD due to an appropriate emollient intervention [6].

\section{Limitations}

The present study discusses a possible approach in the evaluation of core outcomes in children with dry skin and atopic predisposition using recommended scores for $\mathrm{AD}$. So far, the scores are validated only for children with AD.

\section{Statement of Ethics}

The trial was approved by the local ethics committee and complied with the Declaration of Helsinki guidelines.

\section{Disclosure Statement}

The authors have no conflicts of interest to declare. 


\section{References}

1 Simpson EL, Berry TM, Brown PA, Hanifin JM: A pilot study of emollient therapy for the primary prevention of atopic dermatitis. J Am Acad Dermatol 2010;63:587-593.

2 Bohme M, Svensson A, Kull I, Wahlgren CF: Hanifin's and Rajka's minor criteria for atopic dermatitis: which do 2-year-olds exhibit? J Am Acad Dermatol 2000;43(5 pt 1):785-792.

3 Pons-Guiraud A: Dry skin in dermatology: a complex physiopathology. J Eur Acad Dermatol Venereol 2007;21(suppl 2):1-4.

4 Wakamori T, Katoh N, Hirano S, Kishimoto S, Ozasa K: Atopic dermatitis, dry skin and serum IgE in children in a community in Japan. Int Arch Allergy Immunol 2009;149: 103-110.

5 Asher MI, Montefort S, Björkstén B, et al: Worldwide time trends in the prevalence of symptoms of asthma, allergic rhinoconjunctivitis, and eczema in childhood: ISAAC Phases One and Three repeat multicountry crosssectional surveys. Lancet 2006;368:733-743.

6 Simpson EL, Chalmers JR, Hanifin JM, et al: Emollient enhancement of the skin barrier from birth offers effective atopic dermatitis prevention. J Allergy Clin Immunol 2014;134: 818-823.

7 Schario M, Lünnemann L, Stroux A, Reisshauer A, Zuberbier T, Blume-Peytavi U, Garcia Bartels N: Children with dry skin and atopic predisposition: daily use of emollients in a participant-blinded, randomized, prospective trial. Skin Pharmacol Physiol 2014; 27:208.

8 Schmitt J, Spuls PI, Thomas KS, et al: The Harmonising Outcome Measures for Eczema (HOME) statement to assess clinical signs of atopic eczema in trials. J Allergy Clin Immunol 2014;134:800-807.

9 Schmitt J, Langan S, Deckert S, et al: Assessment of clinical signs of atopic dermatitis: a systematic review and recommendation. J Allergy Clin Immunol 2013;132:1337-1347.

10 Smidesang I, Saunes M, Storrø O, Øien T, Holmen TL, Johnsen R, Henriksen AH: Atopic dermatitis among 2-year olds; high prevalence, but predominantly mild disease - the PACT study, Norway. Pediatr Dermatol 2008; 25:13-18.

11 Kunz B, Oranje AP, Labrèze L, Stalder JF, Ring J, Taïeb A: Clinical validation and guidelines for the SCORAD index: consensus report of the European Task Force on Atopic Dermatitis. Dermatology 1997;195:10-19.

12 Ricci G, Bendandi B, Bellini F, Patrizi A, Masi $\mathrm{M}$ : Atopic dermatitis: quality of life of young Italian children and their families and correlation with severity score. Pediatr Allergy Immunol 2007; 18:245-249.

13 Stalder JF, Barbarot S, Wollenberg A, et al: Patient-Oriented SCORAD (PO-SCORAD): a new self-assessment scale in atopic dermatitis validated in Europe. Allergy 2011;66:11141121.
14 Rehal B, Armstrong AW: Health outcome measures in atopic dermatitis: a systematic review of trends in disease severity and qualityof-life instruments 1985-2010. PLoS One 2011;6:e17520.

15 Charman C, Williams H: Outcome measures of disease severity in atopic eczema. Arch Dermatol 2000;136:763-769.

16 Severity scoring of atopic dermatitis: the SCORAD index. Consensus Report of the European Task Force on Atopic Dermatitis. Dermatology 1993;186:23-31.

17 Gelmetti C, Boralevi F, Seité S, et al: Quality of life of parents living with a child suffering from atopic dermatitis before and after a 3 -month treatment with an emollient. Pediatr Dermatol 2012;29:714-718.

18 Barbarot S, Gagnayre R, Bernier C, et al: A guide for education programs in atopic dermatitis (in French). Ann Dermatol Venereol 2007; 134:121-127.

19 Vourc'h-Jourdain M, Barbarot S, Taieb A, et al: Patient-oriented SCORAD: a self-assessment score in atopic dermatitis. A preliminary feasibility study. Dermatology 2009;218: 246-251.

20 Kvien TK, Heiberg T: Patient perspective in outcome assessments - perceptions or something more? J Rheumatol 2003;30:873-876.

21 Coutanceau C, Stalder JF: Analysis of correlations between patient-oriented SCORAD (PO-SCORAD) and other assessment scores of atopic dermatitis severity and quality of life. Dermatology 2014;229:248-255.

22 van Oosterhout M, Janmohamed SR, Spierings $\mathrm{M}$, Hiddinga J, de Waard-van der Spek FB, Oranje AP: Correlation between objective SCORAD and three-item severity score used by physicians and objective PO-SCORAD used by parents/patients in children with atopic dermatitis. Dermatology 2015;230: 105-112.

23 Trojahn C, Schario M, Dobos G, Blume-Peytavi U, Kottner J: Reliability and validity of two in vivo measurements for skin surface topography in aged adults. Skin Res Technol 2015;21:54-60.

24 Tronnier H, Wiebusch M, Heinrich U, Stute R: Surface evaluation of living skin. Adv Exp Med Biol 1999;455:507-516.

25 Diepgen TL, Sauerbrei W, Fartasch M: Development and validation of diagnostic scores for atopic dermatitis incorporating criteria of data quality and practical usefulness. J Clin Epidemiol 1996;49:1031-1038.

26 Diepgen T: Berufliche Rehabilitation von hautkranken Beschäftigten. Dtsch Ärztebl 1991, vol 93.

27 Oranje AP, Glazenburg EJ, Wolkerstorfer A, de Waard-van der Spek FB: Practical issues on interpretation of scoring atopic dermatitis: the SCORAD index, objective SCORAD and the three-item severity score. Br J Dermatol 2007;157:645-648.
28 Lawson V, Lewis-Jones MS, Finlay AY, Reid P, Owens RG: The family impact of childhood atopic dermatitis: the Dermatitis Family Impact Questionnaire. Br J Dermatol 1998;138: 107-113.

29 Ring J, Alomar A, Bieber T, et al: Guidelines for treatment of atopic eczema (atopic dermatitis) part II. J Eur Acad Dermatol Venereol 2012;26:1176-1193.

30 Ring J, Alomar A, Bieber T, et al: Guidelines for treatment of atopic eczema (atopic dermatitis) part I. J Eur Acad Dermatol Venereol 2012;26:1045-1060.

31 Simpson EL, Keck LE, Chalmers JR, Williams HC: How should an incident case of atopic dermatitis be defined? A systematic review of primary prevention studies. J Allergy Clin Immunol 2012;130:137-144.

32 Schäfer T, Dockery D, Krämer U, Behrendt $\mathrm{H}$, Ring J: Experiences with the severity scoring of atopic dermatitis in a population of German pre-school children. Br J Dermatol 1997; 137:558-562.

33 Broberg A, Svensson A, Borres MP, Berg R Atopic dermatitis in 5-6-year-old Swedish children: cumulative incidence, point prevalence, and severity scoring. Allergy 2000;55: 1025-1029.

34 Boralevi F, Saint Aroman M, Delarue A, Raudsepp H, Kaszuba A, Bylaite M, Tiplica GS: Long-term emollient therapy improves xerosis in children with atopic dermatitis. J Eur Acad Dermatol Venereol 2014;28:14561462.

35 Boralevi F, Hubiche T, Léauté-Labrèze C, et al: Epicutaneous aeroallergen sensitization in atopic dermatitis infants - determining the role of epidermal barrier impairment. Allergy 2008;63:205-210.

36 Sahle FF, Gebre-Mariam T, Dobner B, Wohlrab J, Neubert RH.: Skin diseases associated with the depletion of stratum corneum lipids and stratum corneum lipid substitution therapy. Skin Pharmacol Physiol 2015;28:42-55.

37 Richters R, Falcone D, Uzunbajakava N, et al What is sensitive skin? A systematic literature review of objective measurements. Skin Pharmacol Physiol 2015;28:75-83.

38 Proksch E, Lachapelle JM: The management of dry skin with topical emollients - recent perspectives. J Dtsch Dermatol Ges 2005;3: 768-774.

39 Ben-Gashir MA, Seed PT, Hay RJ: Are quality of family life and disease severity related in childhood atopic dermatitis? J Eur Acad Dermatol Venereol 2002;16:455-462.

40 Giordano-Labadie F, Cambazard F, Guillet G, Combemale P, Mengeaud V: Evaluation of a new moisturizer (Exomega milk) in children with atopic dermatitis. J Dermatolog Treat 2006; 17:78-81 